\section{Effect of radiation inside square hollow section under moderate non-symmetric fire}

\author{
Jolanta Bączkiewicz, Sami Pajunen, \\ Markku Heinisuo \\ Laboratory of Civil Engineering, \\ Tampere University of Technology, \\ Tampere, Finland
}

\begin{abstract}
The temperature calculation of hollow steel sections at elevated temperatures is a well-documented and standard procedure. Through this standard procedure, the temperature can be calculated by assuming a uniform gas temperature all around the section, which is called a symmetric fire in this paper. Embedding in surrounding structures or connecting to another steel member results in non-symmetric heat distribution in the member. This non-symmetricity of the surrounding temperature may cause surface-to-surface heat radiation inside the member, thus affecting the steel section temperature distribution. This effect is considered in this paper by adopting analytical and finite element method analysis.
\end{abstract}

\section{Introduction}

The current European standards for fire safety design for steel structures are $\mathrm{EN}$ 1991-1-2 (EC 1), ${ }^{1}$ and EN 1993-1-2 (EC 3). ${ }^{2,3} \mathrm{EC} 3$ is based on the limiting temperature and the moment capacity using the lumped thermal capacity model to predict heat transfer and a steel member's resistance at elevated temperatures. This method assumes that the temperature around the cross-section is symmetrical. However, the steel members used in the structure are usually embedded, which means the fire does not affect equally all sides of the member and is called a non-symmetric fire. The consequence of the non-symmetric fire is the non-uniform heating of the cross-section. Hence, the change of the cross-section properties becomes difficult to predict without any additional requirements. EC 3 includes recommendations for three sides of exposed I-sections and steel slabs ${ }^{3}$ but no unified rules have been introduced for hollow sections. Some studies in the literature presented this problem.

The non-symmetric heating of tubular columns filled with concrete was experimentally tested in Yang et al. ${ }^{4-6}$ and numerically in Heinisuo et al. ${ }^{7}$ The research stud- ies showed that the number of sides on which fire acts has a major influence on the heat distribution and fire resistance. With an increasing number of sides exposed to fire, the fire resistance in the square hollow section (SHS) concrete-filled columns decreases along with the ambient conditions. ${ }^{5}$ Heinisuo et al..$^{7}$ took into consideration different types of embedding materials as well. They compared the temperature distribution in a concrete-filled column surrounded by concrete walls and sandwich panels. The study reveals that the type of embedding strongly influences the temperature distribution inside the column. The concrete wall due to thermal properties isolates the steel column, and the temperature inside the section rises more slowly than in the case when sandwich panels are used. Therefore, the type of embedding material is another important factor in heat transfer analysis; the temperature of the column rises in different phases depending on the surrounding structures.

During non-symmetrical heating, radiation heat exchange occurs between all of the cross-section's heated surfaces. Steel behaves as a diffuse grey surface, which means that the surrounding surface absorbs part of the emitted heat, and the rest is reflected. ${ }^{8}$ The energy balance principles are used to calculate the radiation exchange. The radiative heat transfer from a grey body is then determined based on radiosity and black body emissive power. Considering an enclosure formed with many surfaces, the calculation must include all of the net radiant energy $\left(Q_{t}\right)$ leaving each surface, and all possible combinations of the fraction energy that is leaving one surface and that other surfaces intercept $\left(Q_{l, j}\right){ }^{8}$

To the authors' best knowledge, the only research concerning cross-sectional radiation inside a steel beam is that of Hulkkonen. ${ }^{9}$ In that study, a similar analytical approach as in this study was used for a welded slim floor box beam with a wide bottom flange. The longitudinal radiation research was conducted by Wong, ${ }^{10}$ who investigated the steel pipes subjected to partial fire acting longitudinally along the pipes. Wong proposed a parametrically coded generic element method to solve the heat transfer problem for symmetric fire. His method was proved to be more effective and accurate than EC 3 calculations.

The heat transfer in steel columns under symmetric and localised fires has been thoroughly studied. Zhang et al. ${ }^{11-15}$ published many studies on the thermal response of steel open-section columns. The heat transfer within an SHS column was investigated in Zhang et al. ${ }^{16}$ and Balarupan et al. ${ }^{17}$ Zhang et al. ${ }^{16}$ focused on developing the
Correspondence: Jolanta Bączkiewicz, Laboratory of Civil Engineering, Tampere University of Technology, P.O. Box 600, 33101 Tampere, Finland.

Tel.: +358.401981280.

E-mail: jolanta.baczkiewicz@tut.fi

Key words: Steel member; Hollow section; Heat transfer; Radiation.

Contributions: the authors contributed equally.

Conflict of interest: the authors declare no potential conflict of interest.

Funding: TTY Foundation.

Received for publication: 16 August 2017.

Revision received: 25 July 2018.

Accepted for publication: 27 July 2018.

This work is licensed under a Creative Commons Attribution 4.0 License (by-nc 4.0).

(C) Copyright J. Baczkiewicz et al., 2018

Licensee PAGEPress, Italy

Fire Research 2018; 2:42

doi:10.4081/fire.2018.42

most effective model for simulating the performance of an axially loaded SHS column exposed to localized fire. Meanwhile, Balarupan et al. ${ }^{17}$ tested also SHS columns under axial loading but subjected to uniform temperatures up to $700^{\circ} \mathrm{C}$ to study a steel member's global buckling behaviour. A preliminary study on the thermal response of an SHS joint has been described in Bączkiewicz et al. ${ }^{18}$ The research investigated three KT-joints subjected to standard fire exposure. The research showed that the temperature distribution within a joint is not uniform and that it highly depends on the location of the measured point.

The main conclusion of the literature review is that the radiation effect inside an SHS column has not been studied. Therefore, the goal of the paper is to evaluate if the radiation inside the steel tube should be taken into account considering the thermal distribution under the moderate non-symmetric fire conditions. This study was restricted to moderate non-symmetric cases because it was shown ${ }^{18}$ that the temperature differences near welded tubular joints can be considered moderate. The further scope of this research was to study the behaviour of these joints in fire. The literature review highlights that radiation is a physical phenomenon that appears when a closed element (square, circular, etc.) is heated up non-uniformly. The literature review also shows that the temperature distribution and radiation depend on many fac- 
tors, such as the type of embedding material and the number of heated walls. In this study, due to the lack of previous research on the radiation inside an SHS column, a simple example with a determined temperature around the cross-section was considered. Only the cross-sectional radiation within a square tube was investigated. Future studies may consider more advanced structures, such as joints, floors and walls, to provide more detailed data.

First, symmetric fire was taken into consideration to introduce analytical and numerical models. Numerical calculations were conducted in Abaqus/CAE software and validated with EC 3 method results to provide accurate data. Second, non-symmetric fire was taken into account to study the influence of heat radiation. Finally, the results from the analytical calculations and numerical simulations are presented and summarized.

\section{Materials and Methods}

\section{Boundary conditions for analytical and numerical models}

Heat transfer analysis is based on the first law of thermodynamics. The common practise is to present a law as a principle of the conservation of energy or heat balance. ${ }^{1}$ The principle of the conservation of energy can be written as in Eq. (1):

$\Delta U=Q_{\text {in }}+Q_{\text {out }}$

in which $\Delta U$ is the heat stored in the crosssection within time interval $\Delta t$ [s] per unit length of the steel member; $Q_{i n}$ is the heat transferred into the system; and $Q_{\text {out }}$ is the heat generated within the system. To calculate $Q_{\text {out }}$, the radiation between parts of different temperatures must be taken into account. For uniform heating, thermal radiation $Q_{\text {out }}$ is equal to zero. (2)

According to EC 1 nomenclature in Eq.

$Q_{i n}=\dot{h}_{n e t} A_{m} \Delta t k_{s h}$

in which $k_{s h}$ is the correction factor for the shadow effect, taking into account the radiation and convection between parts of the cross-section. Thermal action $\dot{h}_{\text {net }}\left[\mathrm{W} / \mathrm{m}^{2}\right]$ is given by the net heat flux to the surface of the member for bare steel consisting of the convection $\left(\dot{h}_{n e t, c}\right)$ and radiation $\left(\dot{h}_{n e t, r}\right)$ parts:

$\dot{h}_{n e t}=\dot{h}_{n e t, c}+\dot{h}_{n e t, r}$

The convection part, according to
Newton's law, is as follows:

$\dot{h}_{n e t, c}=\alpha_{c} \cdot\left(\theta_{g}-\theta_{m}\right)$

in which $\alpha_{c}\left[\mathrm{~W} / \mathrm{m}^{2} \mathrm{~K}\right]$ is the convective heat transfer factor; $\theta_{g}\left[{ }^{\circ} \mathrm{C}\right]$ is the gas temperature in the vicinity of the member exposed to fire; and $\theta_{m}\left[{ }^{\circ} \mathrm{C}\right]$ is the member's surface temperature. EC 3 recommends that carbon steel be exposed to a standard fire or external fire where heat transfer factor $\alpha_{c}$ is equal to $25 \mathrm{~W} /\left(\mathrm{m}^{2} \mathrm{~K}\right)$.

The radiation is based on the radiation law of Stefan-Boltzmann and can be presented as follows:

$\dot{h}_{n e t, r}=\phi \varepsilon_{m} \varepsilon_{f} \sigma\left[\left(\theta_{r}+273\right)^{4}-\left(\theta_{m}+273\right)^{4}\right](5)$

in which $\phi$ is the configuration factor; $\sigma$ is the Stefan-Boltzmann constant, 5.67 $10^{-}$ ${ }^{8} \mathrm{~W} / \mathrm{m}^{2} \mathrm{~K}^{4}, \theta_{r}$; is the effective radiation temperature; and $\varepsilon_{f}$ is the emissivity of the fire. The surface emissivity of member $\varepsilon_{m}$ depends on the material applied on the surface. The emissivity of the steel, based on Sadiq et al.'s ${ }^{19}$ test, for example, depends on the type of steel and temperature. For carbon steel at temperatures of $380^{\circ} \mathrm{C}-520^{\circ} \mathrm{C}$, the emissivity varies from $0.28-0.69$. EC 1 recommends the following for the carbon steel constant value: $\varepsilon_{m}=0.7$.

In uniform fires, the same temperature is assigned to the entire cross-section at the same time, and then, heat stored in the cross-section is obtained as follows: ${ }^{20}$

$\Delta U=V \rho c_{\mathrm{a}} \Delta \theta_{a}$

in which $V$ is the volume of the member per unit length $\left[\mathrm{m}^{3}\right] ; \rho$ is the unit mass of steel; $c_{a}$ is the specific heat of steel $[\mathrm{J} / \mathrm{kgK}] ; \Delta t$ is the time interval [s]; and $\Delta \theta_{a}$ is the change of the temperature in the cross-section during time $\Delta t[\mathrm{~s}]$.

The increase of temperature $\Delta \theta_{a}$ during time interval $\Delta t$ in an unprotected steel element substituting the above equations is determined as follows: ${ }^{1}$

$$
\Delta \theta_{a}=\frac{A_{m} / V}{c_{a} \rho_{a}}\left[\varepsilon \sigma\left(\theta_{g}{ }^{4}-\theta_{a}{ }^{4}\right)+\alpha_{c}\left(\theta_{g}-\theta_{a}\right)\right] \Delta t
$$

in which $A_{m} / V$ is the section factor for unprotected steel members $[1 / \mathrm{m}]$.

In the analysis, the beam is subjected to a standard fire temperature-time curve known as the ISO 834 curve, which is defined in Eq. (8):

$\theta_{g}=20+345 \log (8 t+1)$

in which $t$ is time given in minutes.
Finite element model construction for heat transfer

As presented in the previous chapter, the temperature distribution in hollow steel elements was dependent on many factors in a complex way. Therefore, the numerical analysis was used to conduct a precise examination. To provide accurate and reliable numerical results of heat transfer, the created numerical model was first verified and then validated against experimental data.

\section{Numerical model - geometry and mesh generation}

The radiation effect analysis was carried out in the finite element (FE) software Abaqus/CAE. ${ }^{21}$ The model was built from solid three-dimensional elements according to EN 10219-222 and was subjected to transient response heat transfer analysis. Mesh was created with 20-node parabolic solid hexahedral heat transfer bricks DC3D20 with two layers of solid elements in the wall thickness to provide satisfactory simulations. This is presented in Appendix Figure 1. The models' material properties, such as density, specific heat and conduction, were assumed based on EC $3^{3}$ and are described in section 2. Radiation inside the hollow section was taken into account as interaction module - cavity radiation.

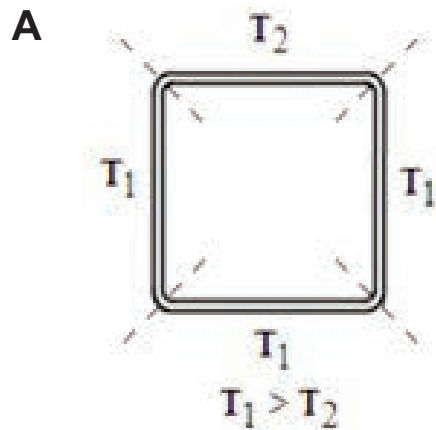

B

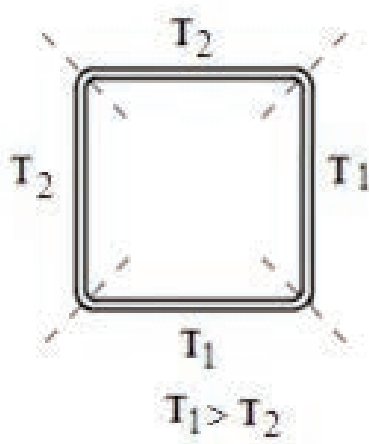

Figure 1. Drawings of heating cases: A) case $\mathrm{F} 1$; B) case $\mathrm{F} 2$. 


\section{Numerical model - verification and vali- dation}

The verification of the assumed mesh model was performed in a few stages. First, the model was tested for symmetric heat distribution. Appendix Figure 2 presents the comparison of: a model build of 20-node quadratic elements (T $100 \times 5)$, model build of an eight-node linear element (8n_uniform), model build of 20-node quadratic elements with a denser mesh grid (20n uniform_D) and model build of eight-node linear elements with a denser mesh grid (8n_uniform_D). It can be seen that for symmetric heating, no significant differences in the heat transfer results were observed. All models followed the same time/temperature curve.
Next, the model was verified for nonsymmetric heating. The same types of models as for symmetric heating were compared. The verification is illustrated in Appendix Figure 3, separately for a warmer wall - for example, a wall subjected to standard ISO 834 curve heating (T200_warm50 - model with 20-node quadratic elements; T200_20n_non-uni_w_D - model with 20-node quadratic elements with a denser mesh grid; T200_8n_non-uni_w model with an eight-node linear element; T200_8n_non-uni_w_D - model with eightnode linear elements with a denser mesh grid) - and for a cooler wall, for example, a wall subjected to $50^{\circ} \mathrm{C}$ lower temperatures of standard ISO 834 curve heating (T200 cold-50, T200 20n non-uni c D, T200_8n_non-uni_c, T200_8n_non- uni c D). As shown in Appendix Figure 3, all analysed models provide similar results. The only exception was the case of eightnode elements with dense mesh, which represents a more narrow difference in the temperature between the warmer and cooler face of a beam than other tested cases do. Based on the analysis and Abaqus/CAE recommendations, ${ }^{21}$ for further analysis, the 20-node elements model with a standard dense mesh grid were assumed to be an accurate representation of the heat transfer problem.

To validate the numerical model of the steel tubular beam, the finite element results of the heat distribution analysis were compared with the experimental results that Baczkiewicz et al. provided. ${ }^{18}$ The experiments that Bączkiewicz et al. ${ }^{18}$ conducted

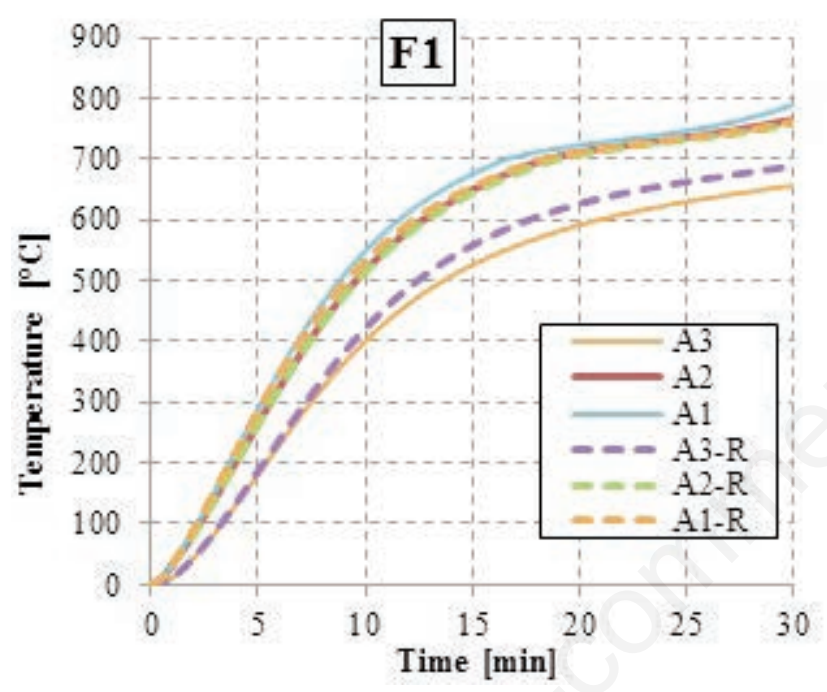

Figure 2. Radiation effect on temperature distribution for steel hollow section $100 \times 100 \times 5$ in case $\mathrm{F} 1$ for $\Delta \mathrm{T}=200^{\circ} \mathrm{C}$.

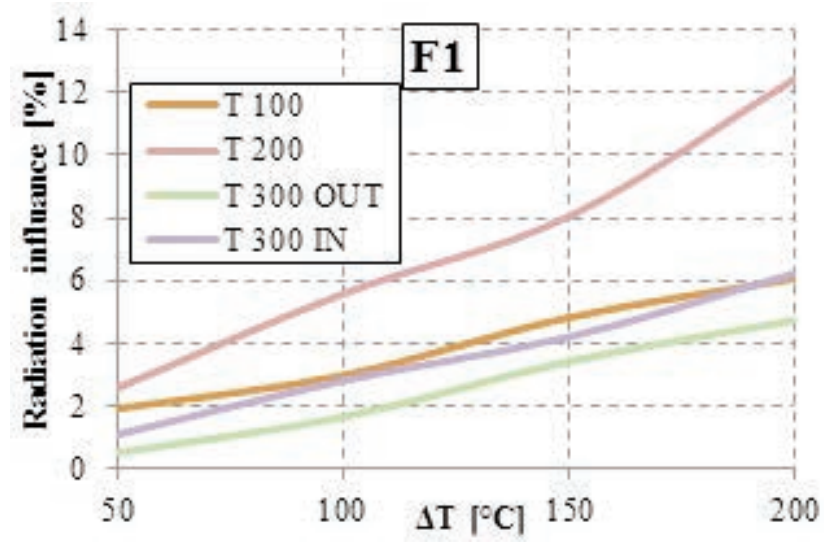

Figure 4. The influence of radiation effect for F1 heating case - FE calculation.

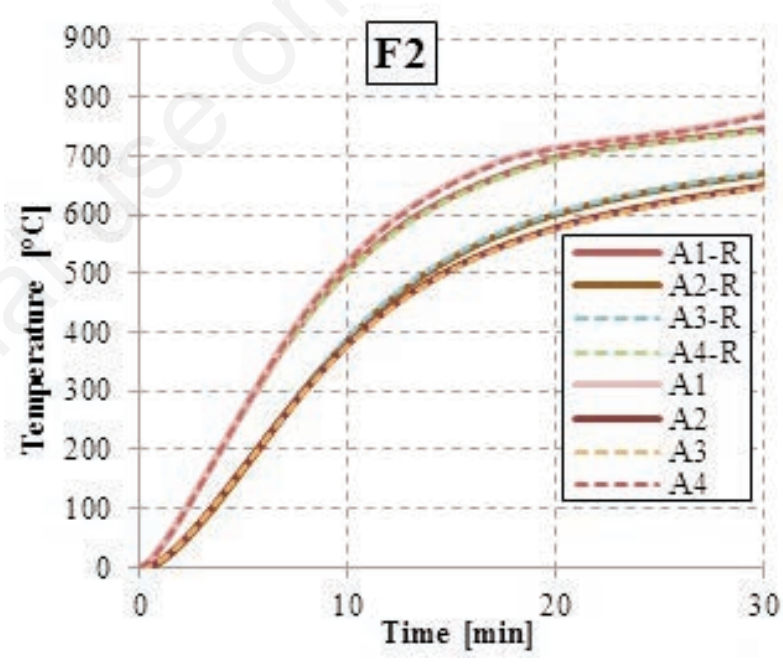

Figure 3. Radiation effect on temperature distribution for steel hollow section $100 \times 100 \times 5$ in case $\mathrm{F} 2$ for $\Delta \mathrm{T}=200^{\circ} \mathrm{C}$.

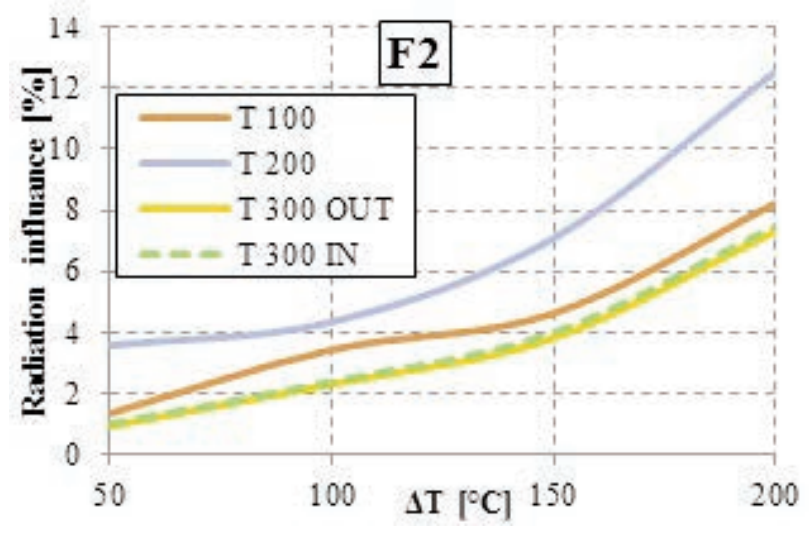

Figure 5. The influence of radiation effect for F2 heating case - FE calculation. 
were concentrated on tubular joints, but it was observed that temperatures far from the brace/chord connection follow the heat distribution for beam elements. Appendix Figure 4 demonstrates a strong correlation between experimental and numerical results, which means that the model provides a fairly solid prediction of steel tubular beam's thermal behaviour of. Therefore, the presented model was used in further analysis.

\section{Analytical model for heat distribution cal- culations}

The analytical model was calculated to test the influence of radiation inside the steel beam. For non-symmetric fire, a model that Mills ${ }^{8}$ proposed was applied. The method introduces $Q_{\text {out }}$, which is radiation from a warmer part of the cross-section to the cooler parts and is defined by the emissive power of the black body $\left(E_{b i}\right)$ and radiation leaving considered surface $\left(J_{i}\right)$. A similar approach was presented in Hulkkonen. ${ }^{9}$

$J_{i}=\varepsilon E_{b i}+(1-\varepsilon)\left(F_{i i} J_{i}+F_{i j} J_{j}+F_{i k} J_{k}\right)$ for $i=1,2,3$

$E_{b i}=\sigma T_{i}^{4}$

in which $J_{i}$ is the radiosity of the surface $\left[\mathrm{W} / \mathrm{m}^{2}\right], E_{b i}$ is the black body emissive power $\left[\mathrm{W} / \mathrm{m}^{2}\right]$ and $F_{i k}$ is the view factor, also described as the configuration factor and shape factor.

The view factor was determined based on the element's geometry. For example, factor $F_{13}$ represents the energy that leaves area $A_{1}$ for area $A_{3}$ to absorb it. A divided cross-section to separate areas is presented in Appendix Figure 5; area $A_{l}$ is the bottom face, $A_{2}$ are the sides of the members and $A_{3}$ is the top face. The main assumption for the analytical calculation was the infinitely long beam.

\section{Results}

Analyses of the numerical and analytical methods were conducted first for the symmetric heating of the beam section and then for non-symmetric heating. The parameter examined in the study due to the influence on radiation was the temperature distribution on the sides of the cross-section. Analyses were performed for the following cross-sections: $100 \times 5,150 \times 5$, $200 \times 5$ and $300 \times 12.5$.

\section{Numerical and analytical results for symmetric heat distribution}

For symmetric heat distribution, an analysis temperature of the gas followed the ISO 834 standard fire curve for Eq. (8). The analytical calculations for symmetric fire were following the method included in EC 3 and are presented in section 2. Due to symmetrically heated beams, no radiation occurred. The analytical result calculation based on the Eurocode and the numerical results are depicted in Appendix Figure 6. As shown in Appendix Figure 6, the temperature of the cross-section depends on its thickness of the wall. For elements with thickness of $5 \mathrm{~mm}$ and $12.5 \mathrm{~mm}$, the numerical calculations gave good agreement with analytical results.

\section{Numerical and analytical results for non-symmetric heat distribution}

Analytical and numerical calculations of the effect of radiation inside the rectangular hollow section was conducted. The effect of radiation was tested for two heating combinations presented in Figure 1 .

For case F1, the temperature of the upper face of the beam was lower than for other members. Three faces marked as $T_{1}$ followed the ISO 834 standard fire curve, and the cooler wall was marked as $T_{2}$. The temperature difference for cooler face was defined by Eq. (15):

$T_{2}=T_{1}-\Delta T$

in which $T_{2}$ is the temperature of gas close to upper face, and $\Delta T$ is the change of gas temperature inside range of $+50^{\circ} \mathrm{C}$ to $+200^{\circ} \mathrm{C}$

For case F2, the temperatures of the bottom and right faces were following the standard fire curve, $T_{1}$, and the temperatures for the left and upper faces were defined based on Eq. 15.

The results are summarized in Appendix Figures 6-12 and in Figures 2 and 3 separately for each case. Both the analytical and numerical results are shown and compared with the temperatures obtained from the EC 3 calculation method. The EC3 assumes that the cross-section was uniformly heated; thus, in the presented results, the temperatures of steel beams are calculated for uniform temperatures $T_{1}$ and $T_{2}$.

\section{Case F1}

The results of the analytical calculations are presented in Appendix Figure 6, which illustrates results obtained for the cross-section $100 \times 5$ with $\Delta T=50^{\circ} \mathrm{C}$. The calculated temperature distribution was compared with the EC 3 calculation method. It can be seen that the temperatures for the warmer wall $\left(A_{1}\right)$ were marginally smaller compared with the EC 3 results, which resulted from the radiation effect. The $A_{1}$ wall transferred part of the heat to wall $A_{3}$; therefore, the temperatures of wall $A_{1}$ were lower. Consequently, the temperature for the cooler wall, $A_{3}$ was slightly higher during the analysis. In cases which considered $\Delta T=100^{\circ} \mathrm{C}, \Delta T=150^{\circ} \mathrm{C}$ and $\Delta T=200^{\circ} \mathrm{C}$, the same phenomena can be observed: temperatures of the wall $A_{1}$ were lower than temperatures calculated according to EC 3 .

Appendix Figure 7 presents similar results but takes into account the results obtained from FE analysis compared with EC3 results. In numerical analysis, the difference in temperature of wall $A_{1}$ ('FEMF1_A1) and wall $A_{2}$ ('FEM-F1_A2) was minimal, whereas the temperatures of wall $A_{3}$ ('FEM-F1_A3') were remarkably lower. In general, the temperatures for all walls of the cross-sections obtained from numerical analysis reached the values in between EC 3 's temperatures, but the differences especially for wall $A_{1}$ and $A_{2}$ were very small. Meanwhile, the differences between the reached temperatures for wall $A_{3}$ were at the maximum point around $30^{\circ} \mathrm{C}$ at the 10 th minute.

However, comparing the analytical results with $\mathrm{FE}$ analysis showed that the temperatures obtained based on Mill's method reached higher values than temperatures from the numerical analysis did. This could be resulting from the bigger sensitivity of the numerical model than of the analytical model, which provided more accurate results for small geometries.

Figure 2 depicts the comparison of numerical analysis for cases when the radiation effect inside the beam was taken into consideration (A1-R, etc.) with cases when the radiation was omitted for $\Delta T=200^{\circ} \mathrm{C}$. It can be noticed that the extreme temperatures were reached with the model with no included radiation effect. The influence of emitting the lower temperatures from a wall (A3) to the other walls and vice versa was not considered, although it explains the wider range of temperatures. The values obtained for wall $A_{2}$ were very close for both models.

The same comparison is illustrated in Appendix Figure 9 but in this case $\Delta T=50^{\circ} \mathrm{C}$. Appendix Figure 9 presents the numerical analysis of cross-section $100 \times 5$ subjected to 30 minutes of non-uniform heating. In Appendix Figure 9A, the radiation inside the beam was not taken into account, whereas in Appendix Figure 9B, the radiation was included. 


\section{Case F2}

In case F2, the cross-section was heated symmetrically (the symmetricity axis in the diagonal of the cross-section), walls $A_{1}$ and $A_{4}$ were following temperature $T_{1}$, and walls $A_{2}$ and $A_{3}$ were following temperature $T_{2}$. Due to two cooler walls, the temperatures reached lower values than in the previous case of F1. For case F2, the same types of analysis were performed. First, in Appendix Figure 10, the analytical calculations were compared with EC 3's result. Second, in Appendix Figure 11, the results of FE analysis and EC 3's calculation are presented. Finally, in Figure 3, the combined results of numerical analysis for models with the included and omitted radiation effect inside the beam are presented, and the comparison of the results are illustrated in Appendix Figure 12.

From the depicted results, it can be seen that if considering the analytical calculation (Appendix Figure 10), the temperatures of the warmer walls $A_{1}$ and $A_{4}$ were lower than the EC3 result calculated for gas temperature $T_{1}$. For cooler walls $A_{2}$ and $A_{3}$, the obtained temperatures during the first eight minutes followed the EC 3 temperatures, but after that time, the temperatures became lower than those of the EC 3 calculations.

However, when taking into consideration the numerical results (Appendix Figure 11), all temperature curves reached values between EC 3 results. The difference between warmer walls $A_{1}$ and $A_{4}$ and EC3 results was the highest at the 18 th minute and reached $20^{\circ} \mathrm{C}$. For cooler walls $A_{2}$ and $A_{3}$, the difference was the biggest at the 10th minute and reached $23^{\circ} \mathrm{C}$.

The same phenomenon can be observed when comparing the numerical results for cases when the radiation was taken into account and when it was omitted (Figure 3). All temperature curves for analysis when radiation effect was included are located in between the results of analysis without a radiation effect. The maximum difference for the warmer walls $A_{1}$ and $A_{4}$ was equal to $18^{\circ} \mathrm{C}$, and for the cooler walls, $\mathrm{A}_{2}$ and $\mathrm{A}_{3}$, it was equal to $21^{\circ} \mathrm{C}$. The illustration of Figure 3 is depicted in Appendix Figure 12, in which the numerical model at the 30th minute of heating is presented. In Appendix Figure 12A, the radiation inside the beam is omitted, and in Appendix Figure 12B the radiation effect is included.

The presented analysis allows one to summarize that the changes in temperature due to the radiation effect are minimal. Moreover, numerical analysis provides the most accurate results of the influence of radiation on a non-uniformly heated crosssection due to the highest sensitivity of the applied calculation method.

\section{Discussion}

The analytical and numerical analysis provided plenty of information about the SHS beams subjected to non-uniform heating. In this section, an analysis of the obtained data is conducted. Figure 4 presents for case $F 1$ the influence of radiation on temperature growth by comparing the percentage differences in temperatures in every step of the analysis between when the radiation was not taken into account and when the radiation was included. The curves in Figure 4 are described as follows: T100 is the square beam of width $100 \mathrm{~mm}$; T200 is the square beam of width $200 \mathrm{~mm}$; T300 OUT is the square beam of width 300 , in which the temperature was measured on top of the wall; and T300 IN is the square beam of width 300 , in which the temperature was measured in the middle of the wall's thickness. It can be summarized that differences in the obtained temperatures wherever the radiation inside the tube was taken into account for small $\Delta T$ (around $50^{\circ} \mathrm{C}$ ) were less than $3 \%$ of all analysed cross-sections. With an increase of the temperature difference $\Delta T$ up to $200^{\circ} \mathrm{C}$, the influence of radiation significantly increased, for instance, from $8 \%$ to $12 \%$ between $150^{\circ} \mathrm{C}$ and $200^{\circ} \mathrm{C}$ for beam crosssection $200 \times 5$. For beam T100, the influence of radiation on temperature varies from $1.9 \%$ for $\Delta T=50^{\circ} \mathrm{C}$ to $6 \%$ for $\Delta T=200^{\circ} \mathrm{C}$. The minimal influence was noticed for T300 IN and T300 OUT and varied, respectively, from $1.0 \%$ for $\Delta T=50^{\circ} \mathrm{C}$ to $6.2 \%$ for $\Delta T=200^{\circ} \mathrm{C}$ and from $0.5 \%$ for $\Delta \mathrm{T}=50^{\circ} \mathrm{C}$ to $4.7 \%$ for $\Delta T=200^{\circ} \mathrm{C}$.

A similar analysis was conducted for case F2, which is illustrated in Figure 5. The curve description is analogical to the ones applied to Figure 4. In this model, the beam of cross-section T200 reveals the highest dependence on radiation influence and is in the range of $3.6 \%$ for $\Delta T=50^{\circ} \mathrm{C}$ up to $12 \%$ for $\Delta T=200^{\circ} \mathrm{C}$. The other results obtained for this case are as follows: for T100, the radiation influence changed from $1.2 \%$ at $\Delta T=50^{\circ} \mathrm{C}$ to $8 \%$ for $\Delta T=200^{\circ} \mathrm{C}$. For $\mathrm{T} 300$, the results were very similar and low for both T300 IN and T300 OUT, starting with the influence of less than $1 \%$ for $\Delta T=50^{\circ} \mathrm{C}$ and $7 \%$ for $\Delta T=200^{\circ} \mathrm{C}$.

For both heating combinations, the same behaviour was observed for small non-uniformities in heating; for example, for $\Delta T \leq 100^{\circ} \mathrm{C}$, the influence of radiation and the effect on the temperature distribution of the beam were insignificant. However, it was also observed that for the case of F2, the percentage influence of the radiation reached slightly higher values than for case F1. Therefore, it can be con- cluded that the radiation effect depends on the configuration of heating to which the beam is subjected and can determine the temperatures reached by the beam.

\section{Conclusions}

In this paper, the numerical and analytical investigation of the influence of the radiation inside a hollow section subjected to non-symmetric fire was presented. The effect of radiation inside the hollow section was examined for two heating cases (Figure 1) and for different sizes of the cross-sections. The numerical analyses were conducted in FE software Abaqus CAE, and analytical calculations were based on $\mathrm{F}$. Mills, 'Basic Heat \& Mass Transfer' book. ${ }^{8}$ The presented study allows for drawing the following conclusions. i) The comparison of the heat transfers in the hollow sections as calculated with the EC 3 procedure and with the FE analysis temperatures revealed that the Eurocode method is reliable for the symmetric fire phenomena and provide an acceptable approximation of thermal distribution in steel tubular elements. However, this method applies only to uniform heating. ii) The numerical analysis provided the most reliable temperature distribution results for the non-uniformly heated SHS beams. The analytical calculations used a simplified method, which may yield accurate results for small geometries. iii) The influence of the radiation on the temperature distribution of the beam differs between the considered cases of F1 and F2. Therefore, it can be concluded that the type of heating case determines the amount of radiation inside the beam. iv) The influence of radiation inside the steel beam presented in Figures 4 and 5 reveals that for the small differences of temperatures, for example, $\Delta T \leq 100^{\circ} \mathrm{C}$, the radiation had a minor effect on the temperature distribution; less than $3 \%$ for T 200 , about $1 \%$ for T300 and T 100 . The performed research affirms that with increasing non-uniformity of the temperature of beams' walls, the effect of radiation becomes more significant up to $12.5 \%$ for $\triangle T=200^{\circ} \mathrm{C}$ and cross-section $\mathrm{T} 200$. Nevertheless, for small temperature differences, the effect of radiation can be ignored.

In accordance with the presented results, this paper proves that radiation inside a beam has a negligible influence on the beam's heat distribution when the nonuniformity of the temperatures of walls of beams is relatively small $\left(\Delta T \leq 100^{\circ} \mathrm{C}\right)$. Hence, the radiation effect need not be addressed in research on hollow sections at elevated temperatures. In further studies, the natural convection inside a tube with 
non-symmetric fire should be considered as well.

\section{References}

1. EN 1991-1-2: Eurocode 1: Actions on structures. Part 1-2: General actions, Actions on structures exposed to fire. Brussels: European Committee for Standardization (CEN); 2005.

2. Haller M, Cajot L-G, Kesti J, et al. Dissemination of structural fire safety engineering knowledge (DIFISEK). Brussels: Office for Official Publ. of the European Communities; 2008.

3. EN 1993-1-2: Eurocode 3: Design of steel structures. Part 1-2: General rules - Structural fire design. Brussels: European Committee for Standardization (CEN); 2005.

4. Yang H, Liu F, Zhang S. Fire performance of CFST columns in non-uniform fire. Proceedings of Conference Eurosteel 2011;1:1563-8.

5. Yang H, Liu F, Gardner L. Performance of concrete-filled RHS columns exposed to fire on 3 sides. Eng Struct 2013;56:1986-2004.

6. Yang H, Liu F, Zhang S, Lv X. Experimental investigation of concretefilled square hollow section columns subjected to non-uniform exposure. Eng
Struct 2013;48:292-312.

7. Heinisuo M, Jokinen T. Tubular composite columns in a non-symmetrical fire. Mag Civ Eng 2014;49:107-20.

8. Mills AF. Basic Heat and Mass Transfer. 2nd ed. New Jersey: Prentice Hall; 1999.

9. Hulkkonen T. Fire engineering design of composite hat-beam. Licentiate thesis. Helsinki: Helsinki University of Technology; 1996.

10. Wong MB. Temperature analysis of partially heated steel members in fire. J Constr Steel Res 2017;128:1-6.

11. Zhang C, Li GQ. Thermal response of steel columns exposed to localized fires - numerical simulation and comparison with experimental results. J Struct Fire Eng 2011;2:311-7.

12. Zhang C, Silva JG, Weinschenk C, et al. Simulation methodology for coupled fire-structure analysis: modelling localized fire tests on a steel column. Fire Technol 2015;52:239-62.

13. Zhang C, Usmani A. Heat transfer principles in thermal calculation of structures in fire. Fire Safety J 2015;78:8595.

14. Zhang C, Gross JL, McAllister TP, Li GQ. Behaviour of unrestrained and restrained steel columns subjected to localized fire. J Struct Eng 2015;141:04014239.

15. Zhang C, Li GQ. Fire dynamic simula- tion on thermal actions in localized fires in large enclosure. Adv Steel Constr 2012;8:124-36.

16. Zhang C, Zhang Z, Li GQ. Simple vs sophisticated fire models to predict performance of SHS column in localized fires. J Constr Steel Res 2016;120:62-9.

17. Balarupan $M$, Mahendran $M$. Experimental studies of cold-formed steel hollow section columns at elevated temperatures. Proceedings of the Annual Stability Conference Structural Stability Research Council, Toronto; 2014.

18. Bączkiewicz J, Malaska M, Pajunen S, Heinisuo M. Fire design of rectangular hollow section joints. Proceedings of conference Eurosteel 2017;1:2601-9.

19. Sadiq H, Wong MB, Tashan J, et al. Determination of steel emissivity for the temperature prediction of structural steel members in fire. J Mater Civ Eng 2013;25:167-73.

20. Drysdale D. An introduction to fire dynamics. 3rd ed. Chichester: John Wiley \& Sons; 2004.

21. ABAQUS 6.13/CAE User's Manual Dassault Systems; 2013.

22. EN 10219-2: Cold formed welded structural hollow sections of non-alloy and fine grain steels. Tolerances, dimensions and sectional properties. Brussels: European Committee for Standardization (CEN); 2006. 